\title{
Study on the Effect of Different Extraction Methods in Four Pharmacopoeia on the Content and Structural Transformation of Ginsenoside and the Optimization of Extraction Process
}

Kai Sun

Jilin University

Hua Jiang

Shenyang Pharmaceutical University

Pingya Li

Jilin University

Lei Xu

Shenyang Pharmaceutical University

Yaling Deng

Shenyang Pharmaceutical University

Jing Xu

Shenyang Pharmaceutical University

Yuqing Zhao ( $\nabla$ zyq4885@126.com )

Shenyang Pharmaceutical University https://orcid.org/0000-0002-8359-4830

\section{Research}

Keywords: Pharmacopoeia, Extraction method, UPLC-Q-Exactive-MS, Ginsenoside, Response surface methodology

Posted Date: October 11th, 2021

DOI: https://doi.org/10.21203/rs.3.rs-944663/v1

License: (c) (1) This work is licensed under a Creative Commons Attribution 4.0 International License. Read Full License 


\section{Abstract}

Background: In recent years, ginseng products are widely used in various fields. More and more people pay attention to the extraction methods and quality evaluation of ginseng. At present, China, the United States, Europe, Japan and Korea have the quality standards and content determination methods of ginseng. However, due to the different treatment methods adopted before the determination of ginseng samples, the content limits of the index components, such as ginsenoside $R b_{1}, R_{1}$ and $R e$ are also different. There have been literature analyzed the similarities and differences of ginseng content detection methods in pharmacopoeias of different countries, but the comparison of the effects of different methods on ginsenoside content and structural transformation has not been reported.

Methods: In this paper, ginsenosides in ginseng were extracted according to four national Pharmacopoeia, and analyzed quantitatively and qualitatively by UPLC-Q-Exactive-MS and HPLC-UV. Finally, a simple and feasible extraction method was optimized by response surface method.

Results: Twelve kinds of ginsenosides in ginseng were quantitatively analyzed by using the methods of four national pharmacopoeia. Among them, the contents of $\mathrm{Rg}_{1}, \mathrm{Re}$ and $\mathrm{Rd}$ were high, and they were the highest by using unheated J/KP (Japan/Korea Pharmacopoeia) method. Ten kinds of ginsenosides were determined by heated CP (China Pharmacopoeia), USP (the United States Pharmacopoeia) and EP (European Pharmacopoeia) method, and seven kinds of ginsenosides were determined by unheated J/KP method. In the following UPLC-Q-Exactive-MS study, 34, 36, 21 and 19 ginsenosides were identified by CP, USP, EP and J/KP method, respectively. In the optimization of ginsenoside extraction process, an efficient extraction method was selected from the solvent, extraction time, solid-liquid ratio and other factors. In conclusion, through the qualitative and quantitative comparison of CP, USP and EP samples after heating, it can be seen that ginsenoside heating will increase the content of rare saponins, and the heating time is directly proportional to the content of rare saponins.

Conclusion: The pretreatment method has a significant effect on the content determination of ginseng. The analysis of the preparation method and process optimization of the four Pharmacopoeia can provide important reference for the revision of ginseng standard.

\section{Introduction}

Ginseng as a traditional herbal medicine occupies a prominent position in Chinese history. It is reported that the first country in the world to record ginseng is China ${ }^{[1]}$. A wide variety of ginseng products, with the health function of improving human immunity and anti-fatigue ${ }^{[2]}$. In the ginseng product industry, because of its product quality is uneven lead to the price is different, so it is imperative to carry out the research on ginseng quality evaluation ${ }^{[3]}$. Ginsenosides are a family of triterpenoids with tetracyclic triterpenoid skeletons, which are widely regarded as the main active components of Panax ginseng ${ }^{[4-5]}$. There are two main dammarane-type triterpene saponins, inclulding protopanaxatriol (PPT) and protopanaxadiol (PPD) ${ }^{[6]}$. Generally, ginsenosides $\mathrm{Rb}_{1}, \mathrm{Re}, \mathrm{Rd}, \mathrm{Rc}, \mathrm{Rg}_{1}$ and $\mathrm{Rb}_{2}$ are the six major 
ginsenosides in ginseng ${ }^{[7]}$. Ginsenosides have neuroprotective effects and play a role in enhancing cognitive ability and memory ${ }^{[8-10]}$. At present, more than 200 kinds of ginsenosides and non-saponins have been isolated and identified from Panax ginseng ${ }^{[11]}$. Ginsenosides can be converted into secondary saponins and aglycones ${ }^{[12]}$, which are easily absorbed by the human body during processing, and play a superior biological activity in inhibiting tumor cells ${ }^{[13]}$, improving cognitive ability ${ }^{[14]}$, and protecting lung function ${ }^{[15]}$ and so on.

Modern studies have shown that ginsenoside content is an important index to measure the inherent quality of ginseng varieties ${ }^{[16-17]}$. The data show that the standardization index of ginseng products is based on the ratio of total ginsenosides to $R b_{1} / R g_{1}$. Asian ginseng is characterized by $R b_{1} / R g_{1}$ ratio of 1 to 3 , and American ginseng is characterized by a ratio of $\mathrm{Rb}_{1} / \mathrm{Rg}_{1}$ of 10 or more ${ }^{[18]}$. The ginseng quality standards specified in the US Pharmacopoeia (USP), the European Pharmacopoeia (EP), and the Japanese/Korean Pharmacopoeia ( $\mathrm{J} / \mathrm{KP}$ ) are ginsenoside $\mathrm{Rg}_{1}$ and ginsenoside $\mathrm{Rb}_{1}$. The Chinese Pharmacopoeia (CP) of 2015 stipulates that the contents of ginsenosides $R g_{1}, R b_{1}$ and $R e$ can be used as a standard for measuring the quality of ginseng ${ }^{[19-22]}$. Therefore, based on the comprehensive pharmacopoeia of various countries, ginsenoside $\mathrm{Rg}_{1}$ and $\mathrm{Rb}_{1}$ are selected as indicators for detection.

The CP, the USP and the EP all involve heating. According to the literature, the thermal transformation of ginseng will bring about the change of content ${ }^{[23]}$. For example, white ginseng can be turned into red ginseng by heating, and the active components in red ginseng can be doubled by the transformation of white ginseng, especially the rare saponins ${ }^{[24-25]}$. The increase of ginseng content can enhance the activity of ginseng, but due to the deficiency of quantitative methods of ginseng, there is a defect in the quality identification of ginseng, which can't show the real amount of ginsenosides.

Literature has analyzed the similarities and differences of different pharmacopoeia methods by detecting the differences in the content of $\mathrm{Rg}_{1}, \mathrm{Rb}_{1}$, and $\mathrm{Re}$ in ginseng which only involved in the pharmacopoeia. However, the comparative studies on the effects of different pharmacopoeia methods on the content of more kinds of active and rare ginsenosides and their structural transformation have not been reported. This paper is based on the review of relevant literature, the ginseng samples were extracted by CP, USP, EP and $\mathrm{J} / \mathrm{KP}$ methods, in addition to the three ginsenosides $\left(\mathrm{Rg}_{1}, \mathrm{Rb} \mathrm{b}_{1}, \mathrm{Re}\right)$ defined by the pharmacopoeia, 9 other ginsenosides were quantitatively analyzed by HPLC-UV. Meanwhile, in order to further analyze the influence of different pharmacopoeia methods on the structural transformation of ginsenosides, UPLC-QExactive-MS was used for qualitative analysis to compare the ginsenosides. It was found that different pretreatment methods had significant effects on ginsenoside. Therefore, in order to quickly identify the index components of ginsenosides [26], the general response surface methodology was selected. A simple and feasible extraction method was optimized with ginseng total saponins as the index. It is of great significance for the rapid identification and standard revision of ginseng components. The experimental research process is shown in Fig. 1. 


\section{Material And Methods \\ 2.1 Reagents and materials}

KQ3200DB ultrasonic cleaning bath (Kunshan Ultrasonic Instrument Co., Ltd.). Chromatographic grade methanol and acetonitrile are purchased from Fisher Scientific International Inc. Purified water is purchased from Wahaha (Hangzhou, China).

Ginseng sample (Huanren City, Liaoning Province) was identified as 15 years old ginseng by Professor Lu Jincai of Shenyang Pharmaceutical University. A voucher specimen (PT 20200411) was kept in the herbarium of Shenyang Pharmaceutical University. The samples were dried at $45^{\circ} \mathrm{C}$ to constant weight.

\subsection{Preparation of Standard Solutions and Sample Solutions}

Ginseng was treated according to the methods of CP, USP, EP and J/KP. The main difference of the preprocessing is reflected in Table 1 . Weigh $1 \mathrm{mg}$ of 12 ginsenosides $R g_{1}, R e, R h_{1}, R b_{1}, R c, F_{1}, R D, R g_{3}, R g_{5}$, $\mathrm{Rh}_{2}$, PPT and PPD to prepare $1 \mathrm{mg} / \mathrm{mL}$ solution.

Table 1

The main difference of the pre-processing in the four Pharmacopoeia

\begin{tabular}{|c|c|c|c|c|}
\hline $\begin{array}{l}\text { Pharmacopoeia } \\
\text { name }\end{array}$ & Extraction method & Temperature & $\begin{array}{l}\text { Heating } \\
\text { time }\end{array}$ & Reagent \\
\hline $\mathrm{CP}$ & $\begin{array}{l}\text { Trichloromethane } \\
\text { soxhlet } \\
\text { \& butannol ultrasonic } \\
\text { extraction }\end{array}$ & $60^{\circ} \mathrm{C}$ & $3 \mathrm{~h}$ & $\begin{array}{l}\text { Trichloromethane; } \\
\text { Butanol }\end{array}$ \\
\hline USP & $\begin{array}{l}\text { Water bath reflux } \\
\text { extraction }\end{array}$ & $100^{\circ} \mathrm{C}$ & $1 \mathrm{~h}$ & Ethanol-water (4: 6) \\
\hline EP & $\begin{array}{l}\text { Water bath reflux } \\
\text { extraction }\end{array}$ & $100^{\circ} \mathrm{C}$ & $1 \mathrm{~h}$ & $\begin{array}{l}\text { Methanol-water (50:50); } \\
\text { Acetonitrile-water (20: } 80)\end{array}$ \\
\hline $\mathrm{J} / \mathrm{KP}$ & Shake extraction & $\begin{array}{l}\text { Room } \\
\text { temperature }\end{array}$ & - & $\begin{array}{l}\text { Methanol-water (3:5); } \\
\text { Dilute sodium hydroxide } \\
\text { solution; } \\
\text { 0. } 1 \mathrm{~mol} / \mathrm{L} \text { Hydrochloric } \\
\text { acid solution }\end{array}$ \\
\hline
\end{tabular}

\subsection{UPLC-Q-Exactive-MS analysis}

The identifications were performed on an UPLC-Q-Exactive-MS equipped with an electrospray ion source (HESI) and Xcalibur 3.0 software (Thermo-Fisher, USA). The resolution of the full MS was 70000 and the resolution of the dd-MS ${ }^{2}$ was 17500 . The full-scan mode $(\mathrm{m} / \mathrm{z}, 100-1500)$ and Full MS/dd-MS ${ }^{2}$ in positive ion mode were implemented to establish the MS analysis. Auxiliary gas flow rate was 10 arb and 
the ion spray voltage was set at $3.5 \mathrm{KV}$. Capillary temperature was set at $300{ }^{\circ} \mathrm{C}$. The collision energy is set to $\mathrm{n}(\mathrm{CE}) 20,30,50 \mathrm{eV}$.

The chromatographic column was Acquirty UPLC BEH C 18 (2.1 mm $\times 50 \mathrm{~mm}, 1.7 \mu \mathrm{m})$. The column temperature was controlled at $30^{\circ} \mathrm{C}$. The mobile phase was Acetonitrile (B) $-0.01 \%$ formic acid water (A). The flow rate is $0.25 \mathrm{~mL} / \mathrm{min}$. The injection volume was $2 \mathrm{uL}$. Mobile phase elution system was performed in a linear gradient (19-22 \% B at 0-3 min, 22-30 \% B at 3-6 min, 30-32 \% B at 6-9 min, 32-35\% $B$ at 9-16 min, 35-55 \% B at 16-18 min, $55 \%$ B at 18-22 min, 55-70 \% B at 22-26 min, 70-90 \% B at 26-29 $\min , 90-19 \% B$ at $29-29.1 \mathrm{~min}, 19 \% \mathrm{~B}$ at 29.1-32 $\mathrm{min}$ ).

\subsection{Simultaneous determination of individual ginsenosides}

Analyses were performed on a CXTH-3000 HPLC system. The mobile phase consisted of water (A) and acetonitrile (B) at a flow rate of $1.0 \mathrm{~mL} / \mathrm{min}$ through an Agilent $5 \mathrm{HC}-\mathrm{C}_{18}$ column $(250 \times 4.6 \mathrm{~mm})$. Mobile phase elution system was performed in a linear gradient (22-27 \% B at 0-10 min, 27-30 \% B at 10-15 min, $30-32 \% \mathrm{~B}$ at $15-35 \mathrm{~min}, 32-35 \% \mathrm{~B}$ at 35-40 min, 35-40 \% B at 40-43 min, 40-46.9 \% B at 43-48 min, 46.947.6 \% B at 48-50 min, 47.6-48.5 \% B at 50-65 min, 48.5-53 \% B at 65-68 min, 53-65 \% B at 68-73 min, 65$85 \% \mathrm{~B}$ at $73-78 \mathrm{~min}, 85 \% \mathrm{~B}$ at $78-83 \mathrm{~min}, 85-22 \% \mathrm{~B}$ at 83-85 $\mathrm{min}, 22 \% \mathrm{~B}$ at 85-95 min). The column temperature was kept at $30{ }^{\circ} \mathrm{C}$, the UV detection wavelength was $203 \mathrm{~nm}$, and the injection amount was $20 \mu \mathrm{L}$.

\subsection{Optimization of extraction process}

\subsubsection{Extraction method}

All samples were crushed into powder of more than 100 mesh. Weigh $1.0 \mathrm{~g}$ ginseng powder and mix it with different solvents of different volumes. It was placed in ultrasonic extractor and extracted at different time. After extraction, the ginseng powder residue was filtered and discarded, and the filtrate was obtained. Total saponins were calculated.

\subsubsection{Selection of variables}

The content of total ginsenosides extracted by ultrasonic extraction was affected by many factors, such as solvent type, solvent concentration, liquid-solid ratio and extraction time. In order to select the suitable variable range, single factor experiments were carried out on the solvent type (methanol, ethanol, $\mathrm{n}$ butanol), solvent concentration (50-90\%), liquid-solid ratio (10-50 mL/g) and extraction time (20-60 min). The total saponins were extracted under different conditions, one factor was changed each time, and the other three factors remained unchanged.

\subsubsection{Selection of various factors and experimental design}

The experiment investigated the three influencing factors of ethanol concentration $(A)$, the ratio of liquor to material (B) and extraction time (C). According to the optimal level of each factor selected by the single 
factor experiment, the three influencing factors in the response surface method experiment and the level settings are shown in Table 2.

Table 2

Experimental variables and their levels in Box-Behnken Design

\begin{tabular}{|lllll|}
\hline Factor & \multicolumn{3}{l}{ Level } & \\
\cline { 2 - 5 } & Low(-1) & Central(0) & High(1) \\
\hline A: Ethanol concentration (\%) & 60 & 70 & 80 \\
\hline B: The ratio of liquor to material $(\mathrm{mL} / \mathrm{g})$ & 10 & 20 & 30 \\
\hline C: Extraction time (min) & 20 & 30 & 40 \\
\hline
\end{tabular}

\subsubsection{Total ginsenoside content of Ginseng}

Accurately draw $1 \mathrm{~mL}$ of the test solution into a test tube with a stopper glass, and evaporate the solvent under the condition of a constant temperature water bath at $90^{\circ} \mathrm{C}$. After the solvent is completely evaporated, remove it from the water bath. Precisely add $0.2 \mathrm{~mL}$ vanillic aldehyde glacial acetic acid solution and $0.8 \mathrm{~mL}$ perchloric acid solution, shake well, place in a constant temperature water bath at $60^{\circ} \mathrm{C}$ for $15 \mathrm{~min}$, remove and rinse with cold water, quickly reduce the tube temperature to room temperature, then add $5 \mathrm{~mL}$ glacial acetic acid, shake evenly, and let stand for $30 \mathrm{~min}$ at room temperature. Using the reagent as a blank control, the absorbance value was measured using an ultraviolet spectrophotometer at a wavelength of $550 \mathrm{~nm}$.

\section{Results And Discussion}

\subsection{Analysis strategy design}

The strategy of this study includes six steps: Extraction of ginseng from Pharmacopoeia of different countries; Optimization of separation and detection conditions; Research on standard crushing mode; The ginseng samples were identified by UPLC-Q-Exactive-MS; HPLC-UV was used to establish the chromatogram and verify the method; Optimization of ginseng extraction method. This study starts with the optimization of chromatographic separation and detection methods. Then, the ginseng samples were analyzed by UPLC-Q-Exactive-MS. By controlling the error below $5 \mathrm{ppm}$, the molecular formula can be deduced from accurate molecular weight and fragment ions. Only when the molecular formula and fragment ions meet the requirements, can a molecule be identified. The identified ginsenosides were quantitatively analyzed by HPLC-UV. Finally, the extraction process of ginseng was optimized by low temperature ultrasound.

\subsection{Optimization of UPLC-Q-Exactive-MS conditions}

In order to obtain more ginsenosides, it is necessary to optimize the separation and detection conditions of the analytical method. The standard solution of ginseng sample was directly injected into UPLC-Q- 
Exactive-MS, and the mass spectrum parameters including depolymerization potential (DP) and collision energy (CE) were optimized to obtain higher sensitivity. The UPLC conditions were optimized to avoid ion suppression and improve the detection sensitivity. We studied the effects of four different ratios of methanol: water, methanol: $0.1 \%$ formic acid water, acetonitrile: water, acetonitrile: $0.1 \%$ formic acid water on the separation of ginseng. However, the pressure of methanol in organic phase is higher than that of acetonitrile liquid chromatography system, so we choose acetonitrile as the organic phase in mobile phase. And acetonitrile: $0.1 \%$ formic acid water was the best, so we chose acetonitrile: 0.1 formic acid water as the mobile phase for gradient elution.

\subsection{UPLC-Q-Exactive-MS analysis}

MS fragmentation and structure analysis [27]: the main structure of ginsenoside was PPD type and PPT type. The PPD type was linked to the C-3 and/or C-20 position. During cleavage, the glycosidic bond at C20 position was broken first, and a molecule of sugar was lost. If it's a disaccharide, the two molecules lose together. Secondly, the $\mathrm{C}-3$ glycosyl group fell off in turn, accompanied by the loss of $\mathrm{H}_{2} \mathrm{O}$ molecules in the whole process. The PPT type is that the glycosyl group is linked to the $\mathrm{C}-6$ and/or $\mathrm{C}-20$ position. During the cleavage, the $\mathrm{C}-20$ and $\mathrm{C}-6$ sugars were lost first and then successively, accompanied by the loss of $\mathrm{H}_{2} \mathrm{O}$ molecules. The characteristic fragment information of PPD ginsenoside was $M / Z 443,425$, 407. Taking ginsenoside $R b_{2}$ as an example, its molecular weight is $1079.27,[\mathrm{M}+\mathrm{Na}]^{+}, \mathrm{M} / \mathrm{Z}$ was 1101.5801 , and its molecular formula is $\mathrm{C}_{53} \mathrm{H}_{90} \mathrm{O}_{22}$. Then the secondary mass spectrum information was analyzed and M/Z 767.4959 [M-glc-xyl+H] ${ }^{+}, 749.4847\left[\mathrm{mM}-\mathrm{glc}-\mathrm{xyl}-\mathrm{H}_{2} \mathrm{O}+\mathrm{H}\right]^{+}, 605.4420[\mathrm{M}-2 \mathrm{glc}-\mathrm{xyl}+\mathrm{H}]^{+}$, 587.4309 [M-2glc-xyl- $\left.\mathrm{H}_{2} \mathrm{O}+\mathrm{H}\right]^{+}, 443.3875[\mathrm{M}-3 \mathrm{glc}-\mathrm{xyl}+\mathrm{H}]^{+}, 425.3782$ [M-3glc-xyl- $\left.\mathrm{H}_{2} \mathrm{O}+\mathrm{H}\right]^{+}, 407.3674$ [M$3 \mathrm{glc}-\mathrm{xyl}-2 \mathrm{H} 2 \mathrm{O}+\mathrm{H}]^{+}$, which accorded with the structural characteristics of ginsenoside $\mathrm{Rb}_{2}$. The characteristic fragment information of PPT ginsenoside is $M$ / $Z 441,423,405$. Taking ginsenoside $\mathrm{Rh}_{1}$ as an example, its molecular weight is $638.87, \mathrm{M} / \mathrm{Z}$ is $661.4286[\mathrm{M}+\mathrm{Na}]^{+}$, and its molecular formula is $\mathrm{C}_{36} \mathrm{H}_{62} \mathrm{O}_{9}$. Then the secondary mass spectrum information was analyzed and $\mathrm{M} / \mathrm{Z} 621.4354\left[\mathrm{M}-\mathrm{H}_{2} \mathrm{O}+\mathrm{H}\right]^{+}$, $603.4250\left[\mathrm{M}-2 \mathrm{H}_{2} \mathrm{O}+\mathrm{H}\right]^{+}, 459.3816[\mathrm{M}-\mathrm{glC}+\mathrm{H}]^{+}, 441.3721\left[\mathrm{M}-\mathrm{glc}-\mathrm{H}_{2} \mathrm{O}+\mathrm{H}\right]^{+}, 423.3619\left[\mathrm{M}-\mathrm{glc}-2 \mathrm{H}_{2} \mathrm{O}+\mathrm{H}\right]^{+}$, 405.3511 [M-glc- $\left.3 \mathrm{H}_{2} \mathrm{O}+\mathrm{H}\right]^{+}$, which were consistent with the structural characteristics of ginsenoside $\mathrm{Rh}_{1}$. The identification results are shown in Fig. 2 and Table 3. 
Table 3

UPLC-Q-Exactive-MS analysis

\begin{tabular}{|c|c|c|c|c|}
\hline Peak & Identity & $t_{R} / \min$ & Molecular formula & Extracting lon $(\mathrm{m} / \mathrm{z})[\mathrm{M}+\mathrm{H}]^{+}$ \\
\hline 1 & Ginsenoside $\mathrm{Ra}_{3}$ & 11.635 & $\mathrm{C}_{59} \mathrm{H}_{100} \mathrm{O}_{27}$ & 1241.6511 \\
\hline 2 & Ginsenoside $\mathrm{Ra}_{1}$ & 12.786 & $\mathrm{C}_{58} \mathrm{H}_{98} \mathrm{O}_{26}$ & 1211.6404 \\
\hline 3 & Ginsenoside $\mathrm{Rb}_{1}$ & 11.581 & $\mathrm{C}_{54} \mathrm{H}_{92} \mathrm{O}_{23}$ & 1109.6086 \\
\hline 4 & Ginsenoside Rc & 12.582 & $\mathrm{C}_{53} \mathrm{H}_{90} \mathrm{O}_{22}$ & 1079.5985 \\
\hline 5 & Ginsenoside $\mathrm{Rb}_{2}$ & 13.877 & $\mathrm{C}_{53} \mathrm{H}_{90} \mathrm{O}_{22}$ & 1079.5985 \\
\hline 6 & Ginsenoside $\mathrm{Rb}_{3}$ & 18.413 & $\mathrm{C}_{53} \mathrm{H}_{90} \mathrm{O}_{22}$ & 1079.5985 \\
\hline 7 & Notoginsenoside $\mathrm{R}_{3}$ & 10.118 & $\mathrm{C}_{48} \mathrm{H}_{82} \mathrm{O}_{19}$ & 963.55109 \\
\hline 8 & Ginsenoside Ro & 13.026 & $\mathrm{C}_{48} \mathrm{H}_{76} \mathrm{O}_{19}$ & 957.50439 \\
\hline 9 & Ginsenoside Re & 11.661 & $\mathrm{C}_{48} \mathrm{H}_{82} \mathrm{O}_{18}$ & 947.5571 \\
\hline 10 & Ginsenoside Rd & 18.538 & $\mathrm{C}_{48} \mathrm{H}_{82} \mathrm{O}_{18}$ & 947.5571 \\
\hline 11 & Notoginsenoside Fe & 13.961 & $\mathrm{C}_{47} \mathrm{H}_{80} \mathrm{O}_{17}$ & 917.5463 \\
\hline 12 & Quinquefolium Saponin $\mathrm{L}_{10}$ & 19.062 & $\mathrm{C}_{47} \mathrm{H}_{80} \mathrm{O}_{17}$ & 917.5463 \\
\hline 13 & Ginsenoside $\mathrm{Rg}_{1}$ & 5.228 & $\mathrm{C}_{42} \mathrm{H}_{72} \mathrm{O}_{14}$ & 801.4981 \\
\hline 14 & Ginsenoside Rf & 6.593 & $\mathrm{C}_{42} \mathrm{H}_{72} \mathrm{O}_{14}$ & 801.4981 \\
\hline 15 & pseudo-ginsenoside $F_{11}$ & 10.12 & $\mathrm{C}_{42} \mathrm{H}_{72} \mathrm{O}_{14}$ & 801.4981 \\
\hline 16 & Ginsenoside $\mathrm{Rg}_{2}$ & 13.819 & $\mathrm{C}_{42} \mathrm{H}_{72} \mathrm{O}_{13}$ & 785.5009 \\
\hline 17 & Ginsenoside $F_{2}$ & 16.824 & $\mathrm{C}_{42} \mathrm{H}_{72} \mathrm{O}_{13}$ & 785.5009 \\
\hline 18 & (S)-Ginsenoside $\mathrm{Rg}_{3}$ & 11.613 & $\mathrm{C}_{42} \mathrm{H}_{72} \mathrm{O}_{13}$ & 785.5009 \\
\hline 19 & (R)-Ginsenoside $\mathrm{Rg}_{3}$ & 12.198 & $\mathrm{C}_{42} \mathrm{H}_{72} \mathrm{O}_{13}$ & 785.5009 \\
\hline 20 & Ginsenoside $F_{3}$ & 11.302 & $\mathrm{C}_{41} \mathrm{H}_{70} \mathrm{O}_{13}$ & $793.4688[\mathrm{M}+\mathrm{Na}]^{+}$ \\
\hline 21 & Ginsenoside $F_{5}$ & 11.302 & $\mathrm{C}_{41} \mathrm{H}_{70} \mathrm{O}_{13}$ & $793.4688[\mathrm{M}+\mathrm{Na}]^{+}$ \\
\hline 22 & Ginsenoside $\mathrm{Rg}_{5}$ & 7.207 & $\mathrm{C}_{42} \mathrm{H}_{70} \mathrm{O}_{12}$ & 767.4339 \\
\hline 23 & Ginsenoside $\mathrm{Rg}_{4}$ & 9.679 & $\mathrm{C}_{42} \mathrm{H}_{70} \mathrm{O}_{12}$ & 767.4339 \\
\hline
\end{tabular}




\begin{tabular}{|lllll|}
\hline Peak & Identity & $\mathrm{t}_{\mathrm{R}} / \mathrm{min}$ & Molecular formula & Extracting lon(m/z)[M+H $]^{+}$ \\
\hline 24 & Ginsenoside $\mathrm{Rg}_{6}$ & 14.779 & $\mathrm{C}_{42} \mathrm{H}_{70} \mathrm{O}_{12}$ & 767.4339 \\
\hline 25 & Ginsenoside $\mathrm{F} 4$ & 18.056 & $\mathrm{C}_{42} \mathrm{H}_{70} \mathrm{O}_{12}$ & 767.4339 \\
\hline 26 & Ginsenoside $\mathrm{MC}$ & 13.921 & $\mathrm{C}_{41} \mathrm{H}_{70} \mathrm{O}_{12}$ & 755.4929 \\
\hline 27 & Notoginsenoside $\mathrm{T}_{5}$ & 10.849 & $\mathrm{C}_{41} \mathrm{H}_{68} \mathrm{O}_{12}$ & 753.4447 \\
\hline 28 & $\mathrm{RT}_{4}$ & 1.004 & $\mathrm{C}_{36} \mathrm{H}_{62} \mathrm{O}_{10}$ & 655.44043 \\
\hline 29 & RT & 10.169 & $\mathrm{C}_{36} \mathrm{H}_{62} \mathrm{O}_{10}$ & 655.44043 \\
\hline 30 & Ginsenoside $\mathrm{F}_{1}$ & 1.554 & $\mathrm{C}_{36} \mathrm{H}_{62} \mathrm{O}_{9}$ & 639.4464 \\
\hline 31 & Ginsenoside $\mathrm{Rh}_{1}$ & 17.095 & $\mathrm{C}_{36} \mathrm{H}_{62} \mathrm{O}_{9}$ & 639.4464 \\
\hline 32 & Rh & 1.071 & $\mathrm{C}_{36} \mathrm{H}_{60} \mathrm{O}_{9}$ & 637.1878 \\
\hline 33 & Ginsenoside $\mathrm{RK}_{2}$ & 12.783 & $\mathrm{C}_{36} \mathrm{H}_{60} \mathrm{O}_{7}$ & 605.4405 \\
\hline 34 & pseudo-sapogenin & 19.341 & $\mathrm{C}_{30} \mathrm{H}_{52} \mathrm{O}_{5}$ & $515.3712[\mathrm{M}+\mathrm{Na}]^{+}$ \\
\hline 35 & PPT & 28.991 & $\mathrm{C}_{30} \mathrm{H}_{52} \mathrm{O}_{4}$ & 477.3933 \\
\hline 36 & PPD & 23.813 & $\mathrm{C}_{30} \mathrm{H}_{52} \mathrm{O}_{3}$ & 461.3989 \\
\hline
\end{tabular}

Through analysis, it is found that the C-20 position deglycosylation reaction occurs first in the heated conversion process, and the deglycosylation products continue to be converted into other products, as shown in Fig. 3. By summarizing the structural characteristics of the conversion products, the main

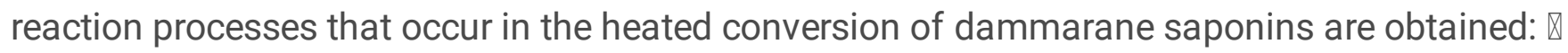
Deglycosylation reaction: preferential removal of the glycosyl substituent at the $\mathrm{C}-20$ position; $\mathbb{}$ Dehydration reaction: $\mathrm{C}-20$ hydroxyl group scavenging reaction with $\beta$ hydrogen at $\mathrm{C}-21$ or $\mathrm{C}-22$ to generate isomers of $\Delta 20(21)$ and $\Delta 20(22)$; $\nabla$ Cyclization reaction: C-20 hydroxyl group is added to $\mathrm{C}-24$ and $\mathrm{C}-25$ double bonds to form six membered rings containing oxygen structure. In addition, some characteristic neutral losses were also observed, that is, the sapogenin ions C-24 and C-25 cleavage to produce $58 \mathrm{Da}$ and the sapogenin ions $\mathrm{C}-20$ and C-22 to produce $84 \mathrm{Da}$, which respectively represent the hydration reaction and structure of the olefin chain of the sapogenin. It can be inferred that the dammarane-type saponins have undergone a cyclization reaction. The above results indicate that dammarane-type saponins can be effectively converted into rare saponins by heating, and HPLC-ESIMS/MS is an effective method for analyzing the structure and pathway of saponins conversion products.

\subsection{Determination of ginsenoside content}


The contents of Ginsenoside $\mathrm{Rg}_{1}, \mathrm{Re}, \mathrm{Rh}_{1}, \mathrm{Rb}_{1}, \mathrm{RC}, \mathrm{F}_{1}, \mathrm{RD}, \mathrm{Rg}_{3}, \mathrm{Rg}_{5}, \mathrm{Rh}_{2}, \mathrm{PPT}$ and PPD were calculated according to the external standard one point method. The liquid phase diagram is shown in Fig. 4. Among the four extraction methods, $\mathrm{Re}, \mathrm{Rg}_{1}, \mathrm{Rb}_{1}$ were the most abundant. Among them, $\mathrm{J} / \mathrm{KP}$ 's extraction method extracted the most original saponins, $R e 2.25 \mathrm{mg} / \mathrm{kg}, \mathrm{Rg}_{1} 0.70 \mathrm{mg} / \mathrm{kg}, \mathrm{Rb} 12.42 \mathrm{mg} / \mathrm{kg}$. The rare saponins $\mathrm{Rh}_{1}, \mathrm{~F}_{1}, \mathrm{Rg}_{3}, \mathrm{Rg}_{5}$ and $\mathrm{Rh}_{2}$ were extracted from the other three extraction methods, and the content of CP was the highest, $\mathrm{Rh}_{1} 0.21 \mathrm{mg} / \mathrm{kg}, \mathrm{F}_{1} 0.05 \mathrm{mg} / \mathrm{kg}, \mathrm{F} 10.05 \mathrm{mg} / \mathrm{kg}, \mathrm{Rg}_{3} 0.02 \mathrm{mg} / \mathrm{kg}, \mathrm{Rg}_{5} 0.09$ $\mathrm{mg} / \mathrm{kg}, \mathrm{Rh} \mathrm{h}_{2} 0.01 \mathrm{mg} / \mathrm{kg}$ respectively. The specific content is shown in the Table 4 .

Table 4

Content of Ginsenoside in different Pharmacopoeia

\begin{tabular}{|lllll|}
\hline & $\mathrm{CP}$ & USP & $\mathrm{EP}$ & $\mathrm{J} / \mathrm{KP}$ \\
\hline $\mathrm{Rg}_{1}(\mathrm{mg} / \mathrm{g})$ & $0.43 \pm 0.022$ & $0.46 \pm 0.026$ & $0.49 \pm 0.029$ & $0.70 \pm 0.037$ \\
$\mathrm{Re}(\mathrm{mg} / \mathrm{g})$ & $1.80 \pm 0.091$ & $1.87 \pm 0.099$ & $1.96 \pm 0.112$ & $2.25 \pm 0.122$ \\
$\mathrm{Rh}{ }_{1}(\mathrm{mg} / \mathrm{g})$ & $0.21 \pm 0.021$ & $0.20 \pm 0.015$ & $0.18 \pm 0.011$ & $0.04 \pm 0.002$ \\
$\mathrm{Rb}_{1}(\mathrm{mg} / \mathrm{g})$ & $2.01 \pm 0.102$ & $2.26 \pm 0.106$ & $2.31 \pm 0.112$ & $2.42 \pm 0.116$ \\
$\mathrm{Rc}(\mathrm{mg} / \mathrm{g})$ & $0.23 \pm 0.013$ & $0.20 \pm 0.011$ & $0.20 \pm 0.012$ & $0.11 \pm 0.006$ \\
$\mathrm{~F} 1(\mathrm{mg} / \mathrm{g})$ & $0.05 \pm 0.004$ & $0.05 \pm 0.003$ & $0.04 \pm 0.002$ & $0.01 \pm 0.001$ \\
\hline $\mathrm{Rd}(\mathrm{mg} / \mathrm{g})$ & $0.39 \pm 0.023$ & $0.30 \pm 0.022$ & $0.22 \pm 0.015$ & $0.06 \pm 0.003$ \\
$\mathrm{Rg}_{3}(\mathrm{mg} / \mathrm{g})$ & $0.02 \pm 0.001$ & $0.01 \pm 0.001$ & $0.01 \pm 0.001$ & - \\
\hline $\mathrm{Rg}{ }_{5}(\mathrm{mg} / \mathrm{g})$ & $0.09 \pm 0.006$ & $0.04 \pm 0.002$ & $0.02 \pm 0.001$ & - \\
\hline $\mathrm{Rh}(\mathrm{mg} / \mathrm{g})$ & $0.01 \pm 0.001$ & $0.01 \pm 0001$ & $0.01 \pm 0.001$ & - \\
\hline $\mathrm{PPT}(\mathrm{mg} / \mathrm{g})$ & - & - & - & - \\
\hline $\mathrm{PPD}(\mathrm{mg} / \mathrm{g})$ & - & - & - & - \\
\hline
\end{tabular}

\subsection{Extraction parameters}

The content of ginsenosides extracted by ultrasonic was affected by the type of solvent, the ratio of liquid to material and the extraction time. In our study, the effects of solvent type, solvent concentration, liquidsolid ratio and extraction time on the extraction rate of ginseng total saponins were investigated. As shown in Fig. 5, all parameters significantly affected the extraction rate of ginsenosides in ginseng. Among the factors of solvent type, ethanol was the best solvent, and the content of ginsenoside was $28.45 \mathrm{mg} / \mathrm{g}$. When $50 \%-70 \%$ ethanol was used as solvent, the content of ginsenoside increased. The extraction time reached the peak in $30 \mathrm{~min}$, and the total ginsenoside content was $25.16 \mathrm{mg} / \mathrm{g}$. When the ratio of liquid to material is $20 \mathrm{~mL} / \mathrm{g}$ and $30 \mathrm{~mL} / \mathrm{g}$, the total saponin content is $33.53 \mathrm{mg} / \mathrm{g}$ and 33.50 
$\mathrm{mg} / \mathrm{g}$, the extraction efficiency is higher. Based on the analysis of economy and other factors, the best level of this factor is the ratio of material to liquid of $20 \mathrm{~mL} / \mathrm{g}$.

\subsection{Effects of the extraction variables on total ginsenosides content}

Taking ethanol concentration (A), liquid to material ratio (B) and extraction time (C) as independent variables, the determination result of total ginsenoside content in the test solution was used as the response value $(\mathrm{Y})$, with the help of Design Expert 8.0.6.1 software. The BBD method was designed accordingly. Three factors and three levels were investigated. The content of total ginsenosides was calculated. The experimental design scheme and the experimental determination of the total saponin content are shown in Table 5.

Table 5

The BBD matrix and the obtained results at different levels of the experimental variables

\begin{tabular}{|lllll|}
\hline No & $\begin{array}{l}\text { A: Ethanol } \\
\text { concentration }(\%)\end{array}$ & $\begin{array}{l}\text { B:the ratio of liquor to } \\
\text { material }(\mathrm{mL} / \mathrm{g})\end{array}$ & $\begin{array}{l}\text { C: extraction } \\
\text { time }(\mathrm{min})\end{array}$ & $\begin{array}{l}\text { Y: Total saponin } \\
\text { content(mg/g) }\end{array}$ \\
\hline 1 & 80 & 20 & 40 & $34.25 \pm 0.86$ \\
\hline 2 & 70 & 30 & 40 & $35.12 \pm 0.97$ \\
\hline 3 & 70 & 20 & 30 & $42.33 \pm 1.05$ \\
\hline 4 & 70 & 20 & 30 & $41.65 \pm 1.16$ \\
\hline 5 & 60 & 20 & 40 & $28.50 \pm 0.59$ \\
\hline 6 & 70 & 10 & 20 & $34.00 \pm 0.82$ \\
\hline 7 & 80 & 30 & 30 & $34.16 \pm 0.75$ \\
\hline 8 & 60 & 30 & 30 & $29.88 \pm 0.68$ \\
\hline 9 & 80 & 10 & 30 & $33.48 \pm 1.03$ \\
\hline 10 & 70 & 30 & 20 & $35.82 \pm 0.68$ \\
\hline 11 & 70 & 10 & 40 & $36.89 \pm 0.96$ \\
\hline 12 & 60 & 20 & 20 & $32.25 \pm 0.72$ \\
\hline 13 & 60 & 10 & 30 & $30.59 \pm 0.78$ \\
\hline 14 & 70 & 20 & 30 & $41.23 \pm 0.99$ \\
\hline 15 & 70 & 20 & 30 & $42.12 \pm 1.21$ \\
\hline 16 & 70 & 20 & 30 & $42.27 \pm 1.12$ \\
\hline 17 & 80 & 20 & $33.67 \pm 0.72$ \\
\hline & 70 & 20 & \\
\hline
\end{tabular}


Table 6

Analysis of variance of experimental regression equation

\begin{tabular}{|c|c|c|c|c|c|c|}
\hline Source & $\begin{array}{l}\text { Sum of } \\
\text { Squares }\end{array}$ & DF & $\begin{array}{l}\text { Mean } \\
\text { Square }\end{array}$ & F Value & $\begin{array}{l}\text { P- } \\
\text { Value } \\
\text { Prob>F }\end{array}$ & Significant \\
\hline Model & 331.17 & 9 & 36.80 & 57.94 & $<0.0001$ & $\star \star$ \\
\hline A & 25.59 & 1 & 25.59 & 40.30 & 0.0004 & ** \\
\hline B & $4.51 \times 10^{-5}$ & 1 & $4.51 \times 10^{-5}$ & $7.11 \times 10^{5}$ & 0.9935 & \\
\hline C & 0.12 & 1 & 0.12 & 0.18 & 0.6830 & \\
\hline$A B$ & 0.49 & 1 & 0.49 & 0.77 & 0.4089 & \\
\hline$A C$ & 4.63 & 1 & 4.63 & 7.29 & 0.0307 & * \\
\hline$B C$ & 3.21 & 1 & 3.21 & 5.06 & 0.0593 & \\
\hline$A^{2}$ & 182.79 & 1 & 182.79 & 287.80 & $<0.0001$ & $\star \star$ \\
\hline$B^{2}$ & 45.89 & 1 & 45.89 & 72.25 & $<0.0001$ & ** \\
\hline$c^{2}$ & 41.94 & 1 & 41.94 & 66.03 & $<0.0001$ & $\star \star$ \\
\hline Residual & 4.45 & 7 & 0.64 & & & \\
\hline $\begin{array}{l}\text { Lack of } \\
\text { Fit }\end{array}$ & 3.56 & 3 & 1.19 & 5.34 & 0.0697 & \\
\hline Pare Error & 0.89 & 4 & 0.22 & & & \\
\hline Cor Total & 335.62 & 16 & & & & \\
\hline Std. Dev & 0.80 & $\mathrm{R}^{2}$ & 0.9868 & & & \\
\hline Mean & 35.78 & Adj $R^{2}$ & 0.9697 & & & \\
\hline C.V. \% & 2.23 & Pred $\mathrm{R}^{2}$ & 0.8263 & & & \\
\hline PRESS & 58.31 & $\begin{array}{l}\text { Adeq } \\
\text { precision }\end{array}$ & 20.825 & & & \\
\hline
\end{tabular}

The experimental data was analyzed by Design Expert 8.0.6.1 software, and the experimental data were subjected to regression fitting to obtain the quadratic regression equation with the total saponin content as the response value $(\mathrm{Y})$.

$Y=41.92+1.79 A+0.002375 B-0.12 C+0.35 A B+1.08 A C-0.90 B C-6.59 A^{2}-3.30 B^{2}-3.16 C^{2}$. 
The size and positive and negative of each coefficient in the equation indicate the degree and direction of the interaction of each factor and each factor on the $Y$ value is the total saponin content of ginseng. It can be seen from the formula that the factors most influencing the total ginsenoside content of ginseng are the ethanol concentration $(A)$, the interaction term of ethanol concentration $(A)$ and extraction time (C), and the second term of extraction time (C) on ginseng total. The effect of saponin content is inferior to ethanol concentration (A). The experimental data was analyzed by Design Expert 8.0.6.1 software, and the results of the variance analysis of the experimental regression equation are shown in Table. 6.

It can be seen from Table. 6 that the $p$-values of the secondary terms of ethanol concentration (A), ethanol concentration (A), liquid material ratio (B) quadratic term, and extraction time (C) are all Less than 0.01 , indicating its impact on the response value is very significant. The $p$-value of the interaction term between ethanol concentration $(A)$ and extraction time $(C)$ is less than 0.05 , indicating that the effect on the response value is significant.

The experimental model p-value $<0.0001$, extremely significant; Lack of fit p-value is 0.0697 , greater than 0.05 , not significant, indicating that the experimental error is small; these two data indicate that the model design is reasonable. The experimental value $\mathrm{R}^{2}=98.68 \%$, greater than $90 \%$, this value can indicate that the experimental model has a good fitting degree, and the predicted value of the model is highly consistent with the experimental results. The experimental method has high credibility and accuracy. A good experimental design, the results Adj $R^{2}$ value should be very close to $R^{2}$, the experimental Adj $R^{2}$ is $96.97 \%$, and the $\mathrm{R}^{2}$ value is $1.71 \%$, indicating that the experimental results do not agree with the model is only $1.71 \%$, the value is very small, it also shows that the experimental model is successfully modeled, and this model can be used to analyze and predict the extraction content of ginseng total saponins in ginseng.

\subsection{Investigating the interaction of factors}

The data was processed using software to predict the effect of three factors (solvent concentration, liquid to material ratio, extraction time) on the total ginsenoside content of ginseng.

It can be seen in Fig. 6A that the interaction of ethanol concentration and liquid to material ratio has effects the content of total ginsenosides in the extraction process. The concentration of ethanol is between $70 \%$ and $75 \%$. When the ratio of material to liquid is between $20-25 \mathrm{~mL} / \mathrm{g}$, the extraction amount of total ginsenoside is the largest, and the ethanol concentration and liquid to material ratio are increased or decreased. The amount of extraction is gradually getting smaller. The ethanol concentration axis contour line is denser than the liquid material than the axis direction contour line, indicating that the ethanol concentration has a greater effect on the total ginseng content than the liquid to material ratio.

It can be seen in Fig. 6B that the ethanol concentration and extraction time have a significant effect on the total saponin content of ginseng during extraction. The ethanol concentration was between $70 \%$ and $75 \%$. When the extraction time was between 30 and 35 minutes, the total extraction amount of ginseng total saponin was the highest. The ethanol concentration and extraction time increased or decreased, and 
the extraction amount of total ginseng gradually changed. From the intensity of the contour line of the ethanol concentration axis and the contour line of the extraction time axis, the contour line in the ethanol concentration axis direction is denser, indicating that the effect of ethanol concentration on the total ginsenoside content is greater than the extraction time.

In Fig. 6C, it can be seen that the ratio of liquid to material and extraction time has a significant effect on the total saponin content of ginseng during extraction. When the liquid to material ratio is between 20-25 $\mathrm{mL} / \mathrm{g}$ and the extraction time is between 30-35 min, the total extraction amount of ginseng total saponins is the highest, regardless of the liquid to material ratio and extraction time, the extraction amount of total ginsenosides. Both are gradually decreasing. The contour map of the interaction between the two shows that the shape of the contour map is elliptical, indicating that the interaction between these two factors is significant ${ }^{[28-29]}$.

\subsection{Optimal extraction process parameters and experimental verification of response surface}

The experimental optimal extraction process model conditions were ethanol concentration $74.37 \%$, liquid to material ratio $21.07 \mathrm{~mL} / \mathrm{g}$, extraction time $33.04 \mathrm{~min}$, theoretical optimal value of total ginsenoside content is $42.34 \mathrm{mg} / \mathrm{g}$.

From the convenience of experimental operation and the accuracy of equipment and instrument, the optimal experimental conditions obtained by software simulation were adjusted to ethanol concentration of $74 \%$, liquid to material ratio of $21 \mathrm{~mL} / \mathrm{g}$, and extraction time of $33 \mathrm{~min}$. To confirm these results, five parallel analyses were evaluated at the optimal level. The average ginsenoside content of ginseng obtained was $42.34 \mathrm{mg} / \mathrm{g}$, the SD value of the standard deviation of the experiment was $0.82 \%$, and the relative standard deviation (RSD) of the experiment was $0.02 \%$, indicating that the established model fits the actual condition better. The model is reliable.

\section{Conclusion}

Ginseng is one of the most commonly used traditional Chinese medicine tonics. For decades, the research on its quality control methods has never stopped. This paper compares and analyzes the similarities and differences of ginseng content detection methods in CP, USP, EP and J/KP. The effects of four Pharmacopoeia pretreatment methods on Ginsenoside Content and the optimization of ginsenoside extraction process were investigated.

In this study, HPLC-UV and UPLC-Q-Exactive-MS were used to analyze the treatment methods of ginseng in four Pharmacopoeia. Twelve kinds of ginsenosides in ginseng were extracted using the methods of four national pharmacopoeia, and quantitatively analyzed by HPLC-UV. Results showed that the content of rare ginsenoside was increased by heating, and the heating time was proportional to the content of rare ginsenoside, as shown in Fig. 7. However, no rare saponins were detected in unheated J/KP method. It is speculated that the original ginsenosides may be transformed into rare ginsenosides after heating. In 
the following study, UPLC-Q-executive-MS was used to analyze the pretreatment methods of ginseng in four pharmacopoeias. The qualitative results of four pharmacopoeias showed that the content of ginsenoside inferred from CP, USP and EP was higher than that of unheated J/KP. It was further verified that the original ginsenosides could be transformed into rare ginsenosides by heating.

The $\mathrm{CP}$, the EP, and the USP all involve the heating process in the process of extracting ginseng samples. Heating can transform ginsenosides, thus affecting the accuracy of the experimental determination results. The J/KP extracts ginsenosides by shaking, and the extraction is incomplete. Based on the $\mathrm{CP}$, in

order to obtain a high quality ginseng content quality standard and avoid the loss of saponin content caused by heating, based on the single factor experiment results, the response surface method was used to optimize the ginseng saponin normal temperature extraction process in ginseng. The regression analysis of the experimental results was done using Design Expert 8.6.0.1 software. The theoretical optimum conditions for extraction of ginsenosides were ethanol concentration $74.37 \%$, liquid to material ratio $21.07 \mathrm{~mL} / \mathrm{g}$, extraction time $33.04 \mathrm{~min}$ and theoretical optimal ginsenoside content of $42.34 \mathrm{mg} / \mathrm{g}$. Considering the convenience of experimental operation and the accuracy of equipment and instruments, the theoretical optimal conditions for ginseng saponin extraction in ginseng were adjusted. The ethanol concentration was adjusted from $74.37-74 \%$, and the liquid to material ratio was adjusted from 21.07 $\mathrm{mL} / \mathrm{g}$ to 21 . In $\mathrm{mL} / \mathrm{g}$, the extraction time was adjusted from $33.04 \mathrm{~min}$ to $33 \mathrm{~min}$. The experiment was carried out to verify that the method was reliable and could be applied to the actual situation. The actual extraction of total ginsenoside content was $42.34 \mathrm{mg} / \mathrm{g}$.

In conclusion, the qualitative and quantitative analysis and comparison of the effects of ginseng pretreatment methods on ginsenosides in Pharmacopoeia of four countries, and the optimization of ginseng pretreatment methods were studied. It provides an important reference for the revision of ginseng quality standard.

\section{Declarations}

\section{Conflict of interest}

All the authors declare that there is no conflict of interest for any of them.

\section{Acknowledgments}

The research was supported by National Natural Science Foundation of China (81903518), Doctoral Research Startup Fund Item of Liaoning Province (2019-BS-232) and Liaoning (FGW) Engineer-ing Technology Research Center for industrial chromatographic preparation of natural innovative drugs materials (2017-1007).

\section{References}


1. Liu MQ, Zhang SL. Overview of ginseng application [J]. Journal of practical internal medicine of traditional Chinese medicine. 2016;30(1):84-5.

2. Ma XT, Wang TX, Jiang DS. An evaluation of the efficacy of a ginseng health food [J]. Journal of health toxicology. 2003;17(1):61-2.

3. Hao JX. Quality evaluation of ginseng products and its influencing factors [D].Jilin agricultural university,2012.

4. Qi LW, Wang CZ, Yuan CS.Ginsenosides from American ginseng: Chemical and pharmacological diversity[J].Phytochemistry,2011,72(8): 689 699.

5. Chung IM, Kim JW, Seguin P,et al. Ginsenosides and phenolics in fresh and processed Korean ginseng(Panax ginseng C.A.Meyer): Effects of cultivation location, year, and storage period[J]. Food Chem. 2012;130(1):73 83.

6. Hong HD, Choi SY, Kim YC, Lee YC, Cho CW. Rapid determination of ginsenosides Rb 1, Rf, and Rg 1 in Korean ginseng using HPLC. J Ginseng Res. 2009.;33:8e12.

7. Rausch WD, Liu S, Gille G, et al. Neuroprotective effects of ginsenosides[J]. Acta Neurobiol Exp. 2006;66(4):369.

8. Christensen JL. Ginsenosides chemistry, biosynthesis, analysis, and potential health effects[J]. Adv Food Nutr Res. 2009;55(55):1-99.

9. Radad K, Moldzio R, Rausch, et al. Ginsenosides and their CNS targets[J]. Cns Neuroscience Therapeutics. 2011;17(6):761-8.

10. Li SS, Jin YP, Yao CL. Research progress on structure and activity of ginseng polysaccharide [J]. Chinese journal of traditional Chinese medicine. 2014;39(24):4709-15.

11. Nan ML, Zhao YW. N.L, Research progress on chemical structure and hypoglycemic activity of ginseng polysaccharide [J]. Chinese pharmacy, 2014(47): 4506-4508.

12. Lim $\mathrm{T}$, Na K, Choi $\mathrm{E}$, et al. Immunomodulating activities of polysaccharides isolated from Panax ginseng[J]. Journalof MedicinalFood. 2004;7(1):1.

13. Shergis JL, Zhang AL, Zhou W, et al. Panax ginseng in randomised controlled trials: a systematic review[J]. Bmc Complementary Alternative Medicine. 2012;27(7):949-65.

14. N.S, G.X, S.X, Effects of ginseng processing on its chemical constituents and pharmacological effects [J]. Chinese pharmacy, 2016(6): 857-859.

15. Yuan Z, Jiang $H$, Zhu X, et al. Ginsenoside Rg3 promotes cytotoxicity of Paclitaxel through inhibiting NF-KB signaling and regulating Bax/Bcl-2 expression on triple-negative breast cancer[J]. Biomed Pharmacother. 2017;89(11):227.

16. Zhang J, Wang SR, Chen QC. Effects of ginsenoside $\mathrm{Rg}_{3}(\mathrm{R}), \mathrm{Rg}_{3}(\mathrm{~S})$, and $\mathrm{Rg}_{5} / \mathrm{Rk}_{1}$ on ethanol-induced improvement of memory in mice [J]. Journal of jilin agricultural university. 2006;28(3):283.

17. Gao R, Xu JR, Li RQ, Protective effect of ginsenoside $\mathrm{Rg}_{5}$ on acute lung injury in septic rats [J]. Advances in modern biomedicine, 2013, 13 (11): 2062. 
18. Men FQ. Chemical composition of ginseng and quality evaluation of ginseng products [J]. Food safety guide, 2016(27): 102 .

19. National pharmacopoeia committee. Pharmacopoeia of the People's Republic of China, [M]. I. Beijing: chemical industry press. 2015: 11-12.

20. The United States Pharmacopoeia40, The National Formulary 35[S].2016:6805[3] [21] European Pharmacopoeia[S]. 9th Edition. 2016:1372.

21. The 17th amendment to the Japanese drug administration, (JPâ@âł) [S].2016:1859.

22. Gao Y, Yu Y, Yu SJ, Chen HL, Liu TS, Qiu ZD, Wei H. Effect of different heating time on the content of 8 kinds of ginsenosides in Panax ginseng[J]. Chinese modern traditional Chinese medicine. 2015;17(04):335-7.

23. Zhang M, Qin KM, Li WD, Yin FZ, Cai H, Cai BC. Study on the changes of Chemical components and its Mechanism in the processing of Ginseng [J]. Chinese Journal of traditional Chinese Medicine. 2014;39(19):3701-6.

24. Zheng Y, Lei L, Ai J, Liang S, Deng X, Shi L, Mei ZN, Ren YS. Study on the changes of Water State and Chemical composition in the process of drying/rehydration of fresh Ginseng [J]. Chinese herbal medicine. 2019;50(14):3302-12.

25. Lin M, Sun W, Gong W, et al. Ginsenoside $\mathrm{Rg}_{1}$ protects against transient focal cerebral ischemic injury and suppresses its systemic metabolic changes in cerabral injury rats[J]. Acta Pharmaceutica Sinica B. 2015;5(3):277-84.

26. Zhang $\mathrm{H}$, Zhang $\mathrm{X}$, Jiang $\mathrm{H}$, Yan J. Analysis of chemical constituents in Shenqi Jiangtang Granules by UPLC-Q-TOF MS/MS [J]. Chinese Traditional Patent Medicine. 2017;39(10):2101-8.

27. Muhammad Adamu,Md Rezaur Rahman,Sinin Hamdan. Formulation optimization and characterization of bamboo/polyvinyl alcohol/clay nanocomposite by response surface methodology [J]. Composites Part B; 2019.

28. Zulkif Sheikh,Shweta Pawar,Virendra. Rathod K. Enhancement of rhamnolipid production through ultrasound application and response surface methodology [J]. Process Biochemistry, 2019, 85.

\section{Figures}




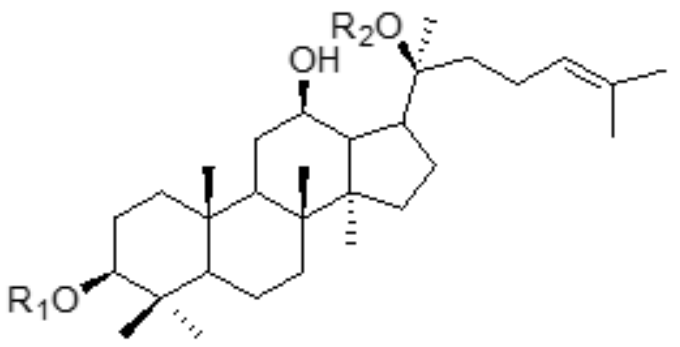

PPD-type

\begin{tabular}{|c|c|c|}
\hline Name & $\mathrm{R}_{1}$ & $\mathrm{R}_{2}$ \\
\hline $\mathrm{Ra}_{1}$ & Glc2-Glc & Glc6-Ara (p) 4-Xyl \\
\hline Ra3 & Glc2-Glc & G1c6-G1c3-Xy1 \\
\hline $\mathrm{Rb}_{1}$ & Glc2-Glc & Glc6-Glc \\
\hline $\mathrm{Rb}_{2}$ & Glc2-Glc & Glc6-Ara (p) \\
\hline $\mathrm{Rb}_{3}$ & Glc2-Glc & Glc6-Xy1 \\
\hline $\mathrm{Rc}$ & Glc2-Glc & Glc6-Ara（f) \\
\hline $\mathrm{Rd}$ & Glc2-Glc & Glc \\
\hline Noto-Fe & Glc & Glc6-Ara（f) \\
\hline$F_{2}$ & Glc & Glc \\
\hline $20(\mathrm{~S})-\mathrm{Rg}_{3}$ & Glc2-Glc & $\mathrm{H}$ \\
\hline 20 (R) $-\operatorname{Rg}_{3}$ & Glc2-Glc & $\mathrm{H}$ \\
\hline Noto- $R_{3}$ & Glc2-Xy1 & Glc \\
\hline PPD & $\mathrm{H}$ & $\mathrm{H}$ \\
\hline
\end{tabular}

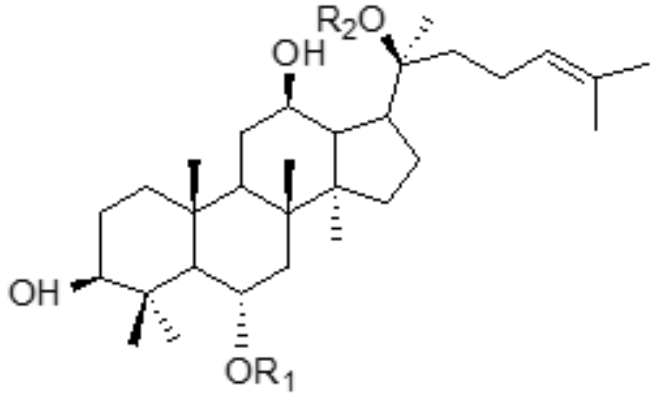

PPT-type

\begin{tabular}{ccc}
\hline Name & $\mathrm{R}_{1}$ & $\mathrm{R}_{2}$ \\
\hline $\mathrm{Re}$ & $\mathrm{Glc} 2-\mathrm{Xyl}$ & $\mathrm{Glc}$ \\
$\mathrm{Rg}_{1}$ & $\mathrm{Glc}$ & $\mathrm{Glc}$ \\
$\mathrm{Rg}_{2}$ & $\mathrm{Glc} 2-\mathrm{Rha}$ & $\mathrm{H}$ \\
$\mathrm{F}_{1}$ & $\mathrm{H}$ & $\mathrm{Glc}$ \\
$\mathrm{F}_{5}$ & $\mathrm{H}$ & $\mathrm{Glc} 2-\mathrm{Glc}$ \\
$\mathrm{F}_{3}$ & $\mathrm{H}$ & Glc6-Ara $(\mathrm{p})$ \\
$\mathrm{Mc}$ & $\mathrm{H}$ & $\mathrm{Glc} 6-\mathrm{Ara}(\mathrm{f})$ \\
$\mathrm{Rf}$ & $\mathrm{Glc} 2-\mathrm{Glc}$ & $\mathrm{H}$ \\
$\mathrm{Rh}$ & $\mathrm{Glc}$ & $\mathrm{H}$ \\
$\mathrm{PPT}$ & $\mathrm{H}$ & $\mathrm{H}$ \\
\hline
\end{tabular}

Figure 1

Experimental process diagram. 


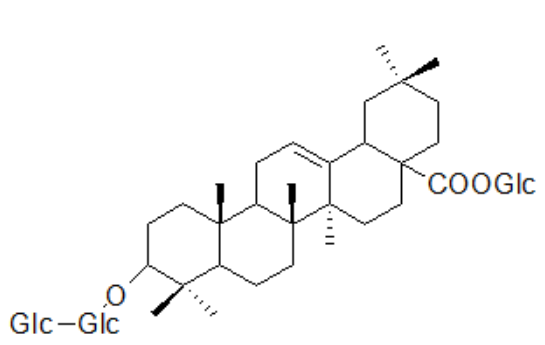

Ginsenoside Ro

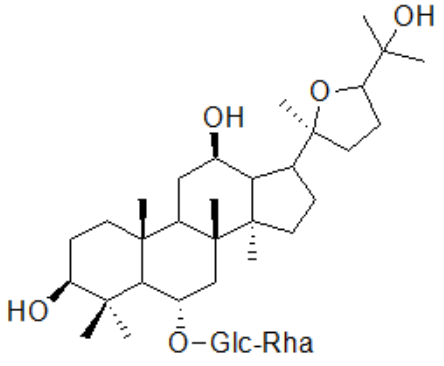

pseudo-ginsenoside $F_{11}$

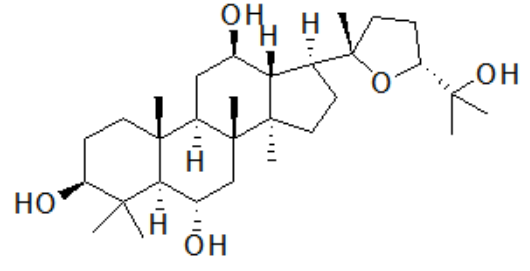

Pseudo sapogenin

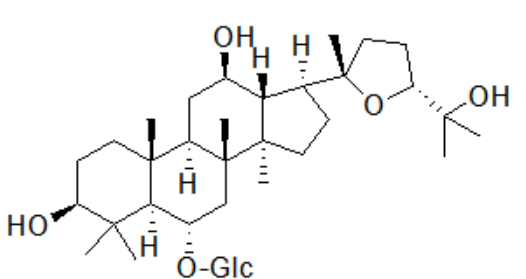

RT 5

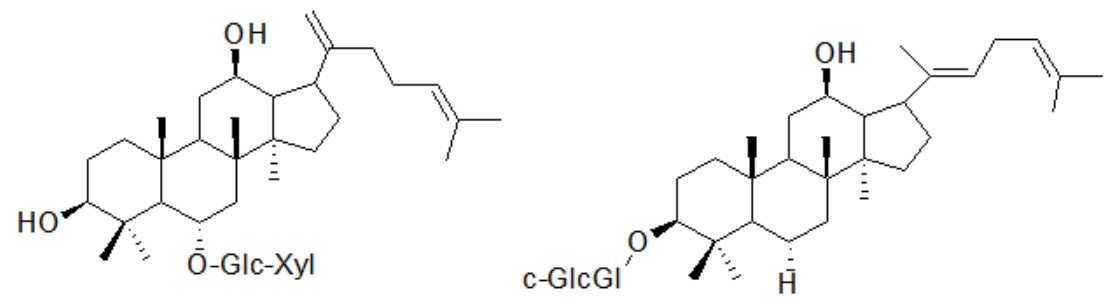

Noto-T5<smiles>C=C(CCC=C(C)C)C1CCC2C3CCC4C(C)(C)[C@@H](OC5CCCCC5)CC[C@]4(C)C3C[C@H](O)C12</smiles>

$\mathrm{Rk}_{2}$

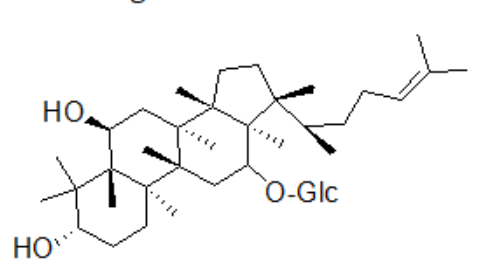

Rhs

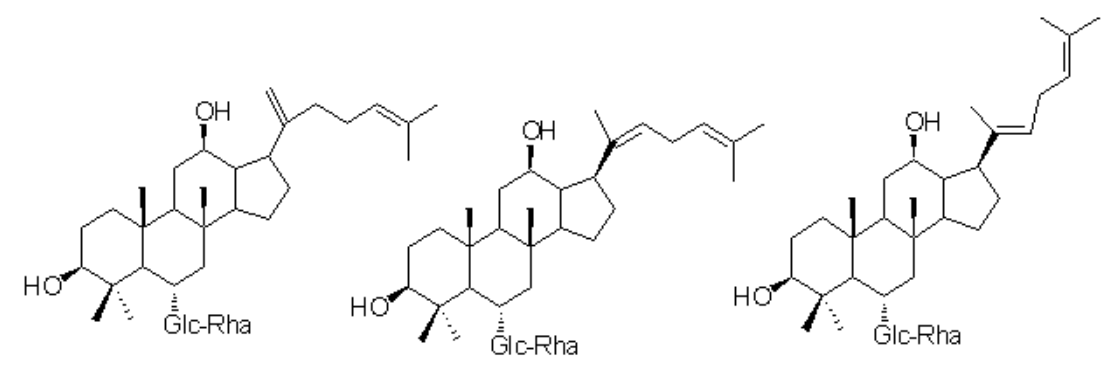

$\mathbf{R g}_{4}$

$\mathbf{R g}_{6}$

$\mathbf{F}_{4}$

\section{Figure 2}

The structure of ginsenosides identified by UPLC-Q-Exactive-MS. 


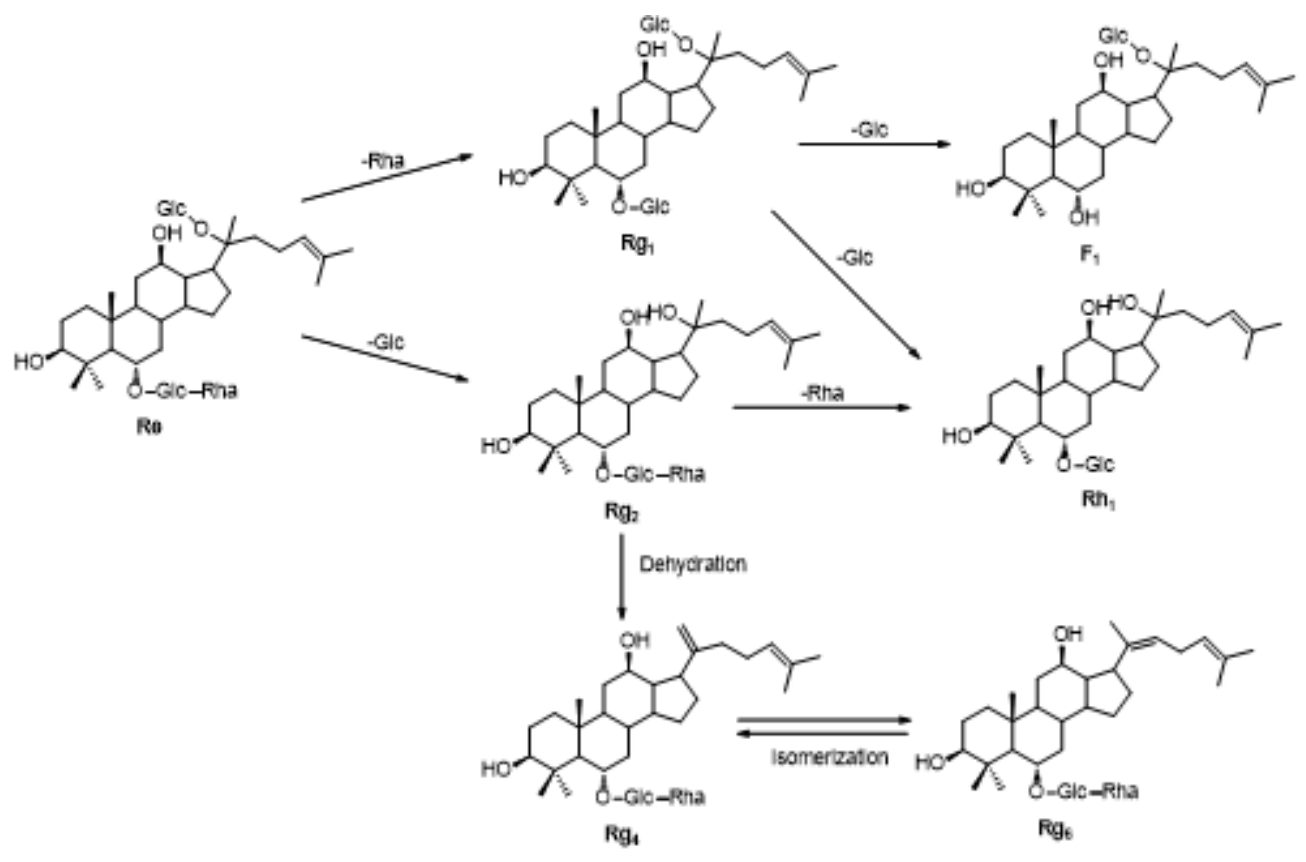

Figure 3

Chemical structures and possible transformation of ginsenosides in heated ginseng. 

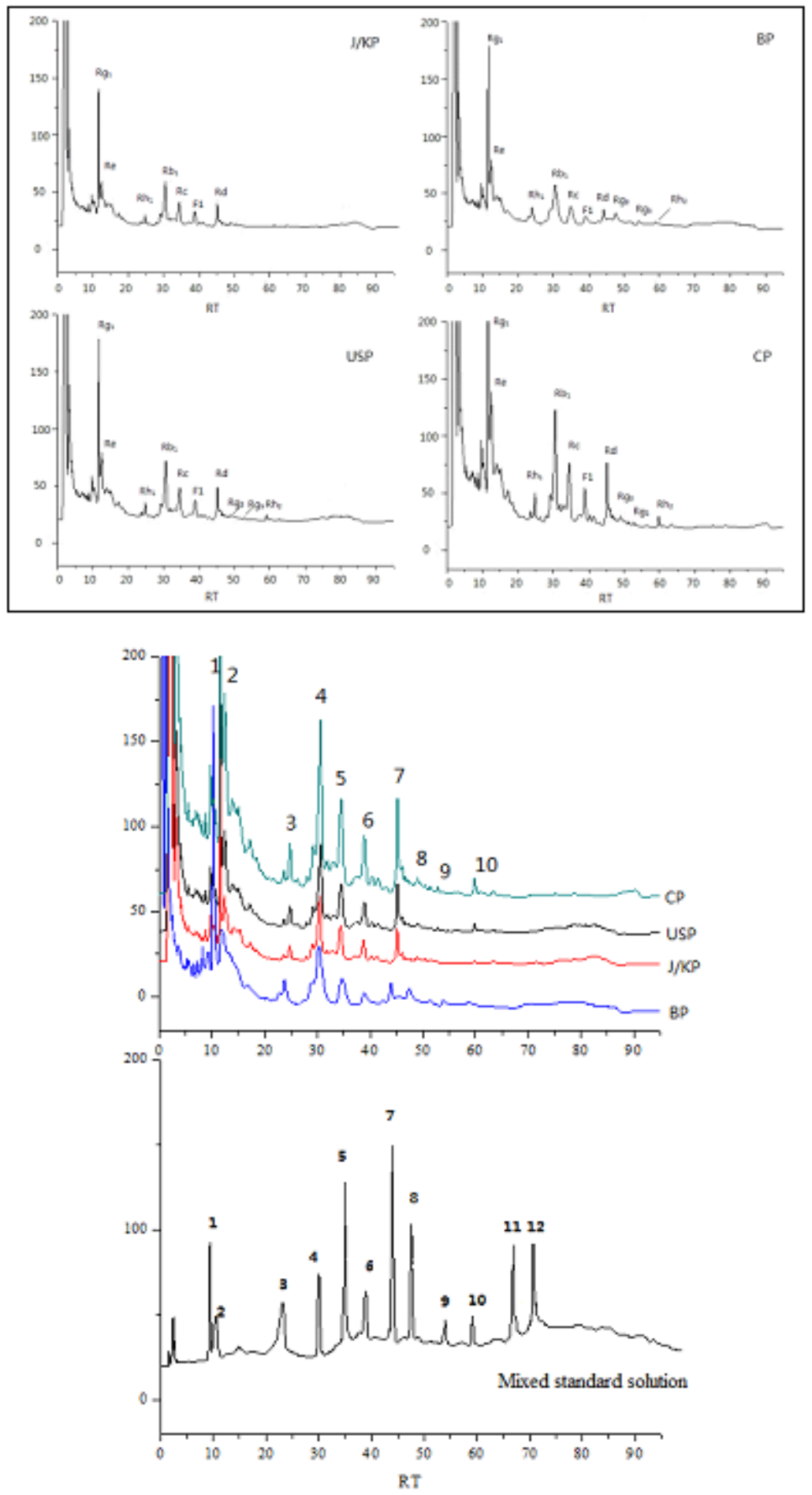

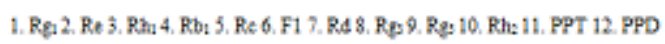

Figure 4

Quantitative chromatogram of ginseng using the four-country pharmacopoeia extraction method. 


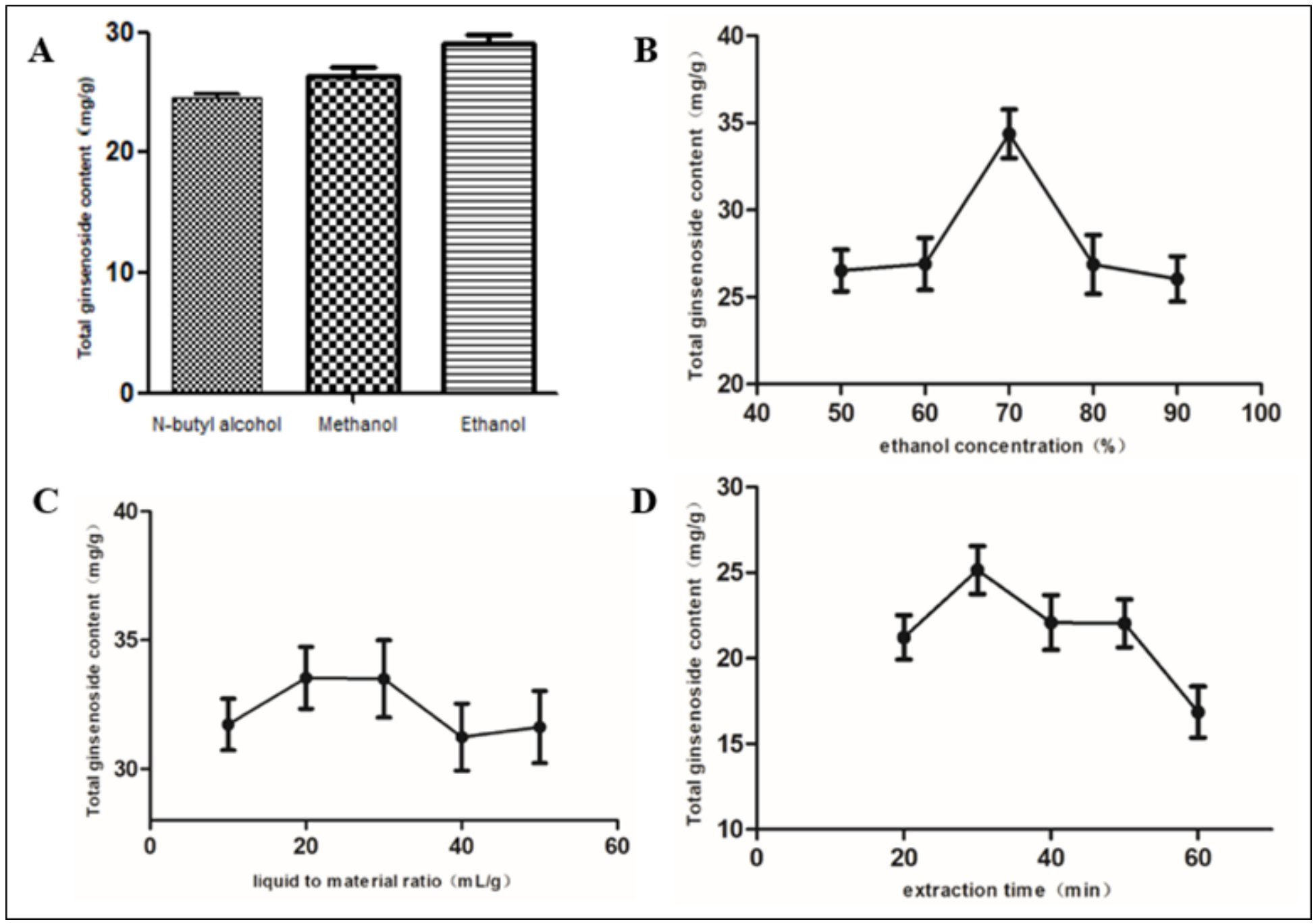

Figure 5

Effects of extraction solvent (A)囚extraction ethanol concentration (B), liquid-solid ratio (C) and extraction time (D), Data are presented as mean \pm S.D. $(n=3)$. 


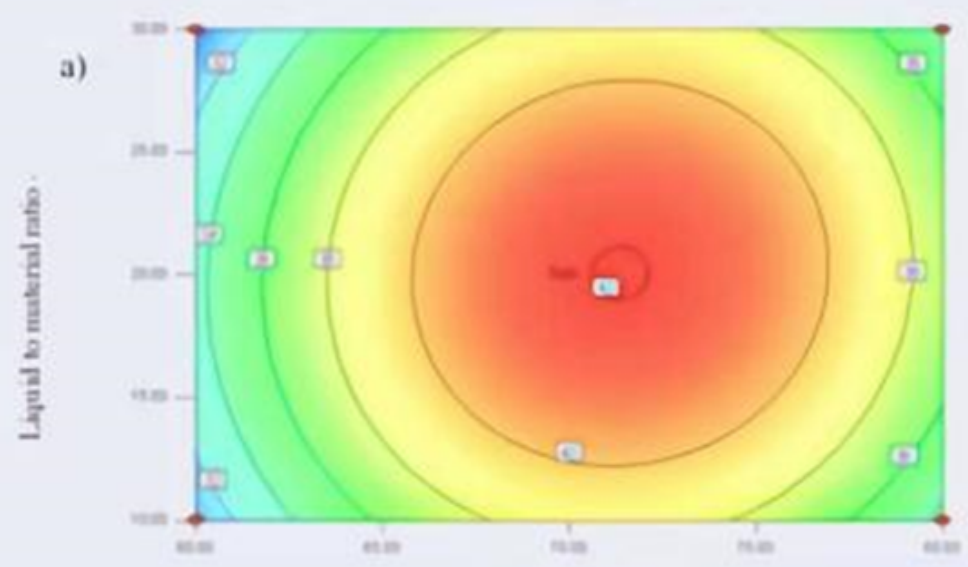

Ethanol concentration

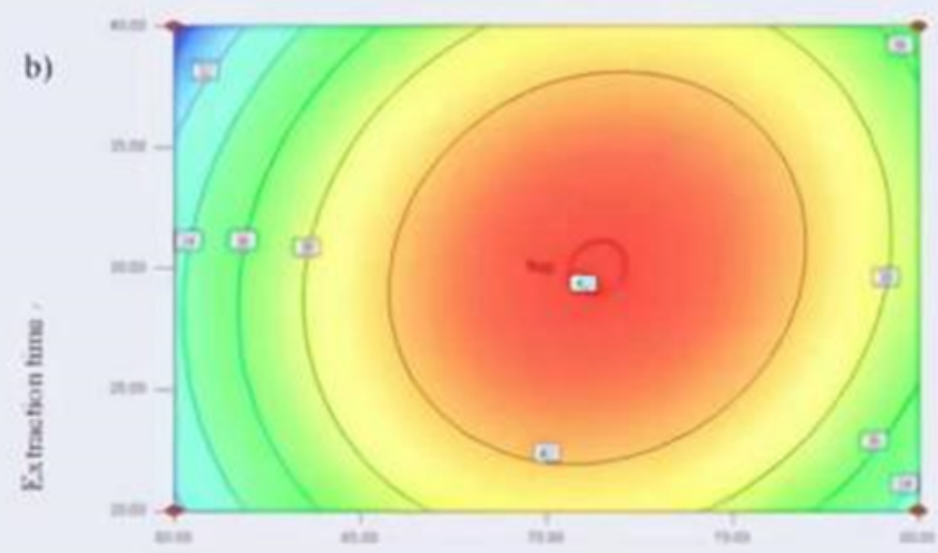

Ethanol concentration .

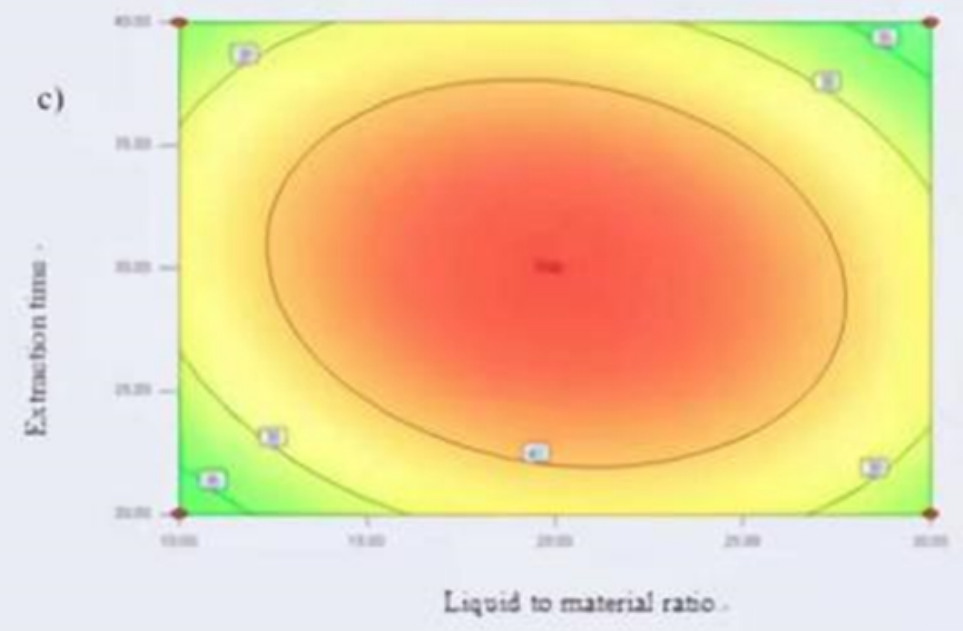

Figure 6

2D contour plots showing the effects of ethanol concentration, liquid to material ratio, and extraction time on the extraction yield of ginsenoside content and their mutual effects. 
methods:

Soxhlet extraction for 3 hours

Saponin content:

$\mathrm{Rg}_{1}: 0.43 \mathrm{mg} / \mathrm{g}$ Rd: $0.39 \mathrm{mg} / \mathrm{g}$

Rare saponins :

$\mathrm{Rg}_{3} 、 \mathrm{Rg}_{5} 、 \mathrm{Rh}_{2}$

methods:

Water bath reflux extraction for 1 hours

Saponin content:

$\mathrm{Rg}_{1}: 0.49 \mathrm{mg} / \mathrm{g}$ Rd: $0.22 \mathrm{mg} / \mathrm{g}$ Rare saponins :

$R g_{3} 、 R g_{5} 、 R h_{2}$
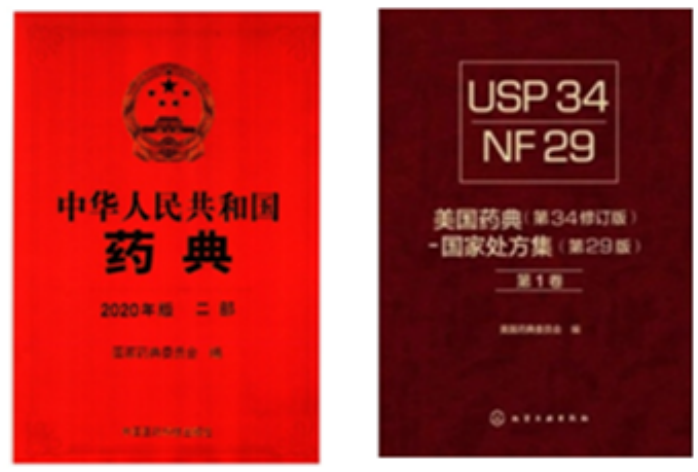

methods:

Water bath reflux extraction for 1 hours

Saponin content:

$\mathrm{Rg}_{1}: 0.46 \mathrm{mg} / \mathrm{g}$ Rd: $0.30 \mathrm{mg} / \mathrm{g}$ Rare saponins :

$\mathrm{Rg}_{3} 、 \mathrm{Rg}_{5} 、 \mathrm{Rh}_{2}$
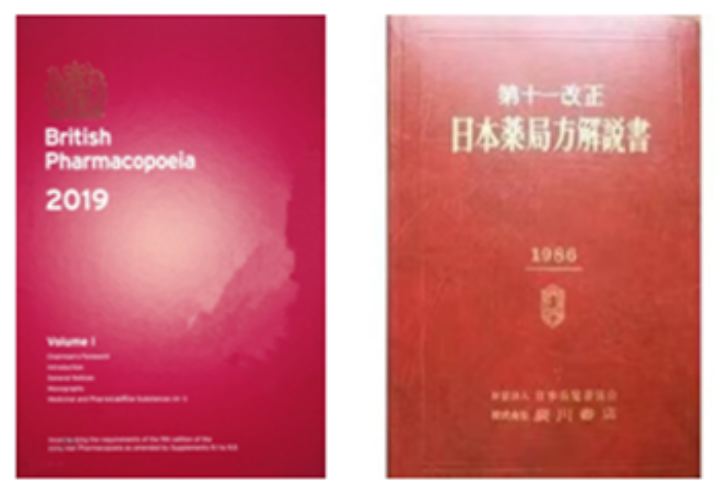

methods:

shake extraction at room temperature

Saponin content:

$\mathrm{Rg}_{1}: 0.70 \mathrm{mg} / \mathrm{g} \mathrm{Rd}: 0.06 \mathrm{mg} / \mathrm{g}$

\section{Figure 7}

The influence of different treatment methods in the pharmacopoeia of the four countries on ginsenosides. 